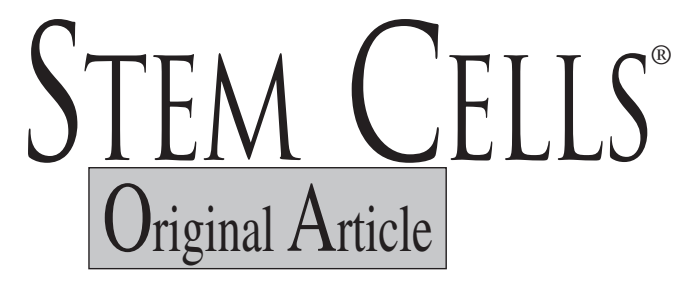

This material is protected by U.S. Copyright law. Unauthorized reproduction is prohibited.

\title{
Fast But Durable Megakaryocyte Repopulation and Platelet Production in NOD/SCID Mice Transplanted with Ex-Vivo Expanded Human Cord Blood CD34+ Cells
}

\author{
Stefania Bruno, ${ }^{\mathrm{a}, \mathrm{b}}$ Monica Gunetti, ${ }^{\mathrm{a}, \mathrm{b}}$ Loretta Gammaitoni, ${ }^{\mathrm{a}, \mathrm{b}}$ Eliana Perissinotto, ${ }^{\mathrm{a}, \mathrm{b}}$ Luisa \\ Caione, ${ }^{\mathrm{a}, \mathrm{b}}$ Fiorella Sanavio, ${ }^{\mathrm{a}}$ Franca Fagioli, ${ }^{\mathrm{c}}$ Massimo Aglietta,,${ }^{\mathrm{a}, \mathrm{b}}$ Wanda Piacibello ${ }^{\mathrm{a}, \mathrm{b}}$ \\ a'Department of Oncological Sciences, University of Torino Medical School, ${ }^{b}$ Division of Clinical \\ Oncology, Institute for Cancer Research and Treatment, Candiolo, Torino, Italy; \\ ${ }^{\mathrm{c}}$ The Pediatric Department, University of Torino Medical School, Torino, Italy
}

Key Words. Cord blood $\cdot C D 34^{+}$cell expansion $\cdot$ NOD/SCID $\cdot$ Megakaryocyte engraftment

\begin{abstract}
We have previously established a stroma-free culture with Flt-3 ligand (FL), stem cell factor (SCF), and thrombopoietin (TPO) that allows the maintenance and the expansion for several weeks of a cord blood (CB) $\mathrm{CD}^{+} 4^{+}$ cell population capable of multilineage and long-lasting hematopoietic repopulation in non-obese diabetic/ severe combined immunodeficient (NOD/SCID) mice.

In this work the kinetics of megakarocyte (Mk)engraftment that is often poor and delayed in CB transplantation, and human platelet (HuPlt) generation in NOD/SCID mice of baseline $\mathrm{CD}^{+} 4^{+}$cells $\left(\mathrm{b34} 4^{+}\right.$), and of $\mathrm{CD34}^{+}$cells reisolated after a 4-week expansion with FL+SCF+TPO $\left(4 \mathrm{w} 34^{+}\right)$were compared.

With $\mathrm{b34}^{+}$cells Mk-engraftment was first seen at week $3\left(\mathrm{CD}^{4} 1^{+}: 0.4 \%\right) ; 4 w 34^{+}$cells allowed a more rapid

Mk-engraftment (at weeks 2 and 3 the $\mathrm{CD41}^{+}$cells were $0.3 \%$ and $0.8 \%$ ). Circulating HuPlts were first seen at weeks 2 and 1, respectively.

Mk-engraftment levels of $\mathrm{b34}^{+}$and $4 \mathrm{w} 34^{+}$cells 6-8 weeks after transplantation were similar $(12 \pm 3.5$ versus $15 \pm 5 \% \mathrm{CD}^{+}{ }^{+} ; 1.3 \pm 0.5$ versus $1.8 \pm 0.5 \% \mathrm{CD}^{+} 1^{+}$cells $)$. Also serial transplant experiments were performed with expanded and reselected CB cells. In secondary and tertiary recipients the Mk population was detected with bone marrow fluorescence-activated cell sorter analysis; these experiments indicate the effective long-term repopulation of expanded cells. Selected $\mathrm{CD34}^{+}$cells after a 4-week expansion with FL+SCF+TPO are more efficient in Mk engraftment than the same number of unmanipulated cells. Stem Cells 2004;22:135-143

INTRODUCTION

The numbers of hematopoietic progenitors and stem cells in cord blood (CB) may be enough to support engraftment in children, but their ex-vivo expansion might be required to successfully engraft an adult. Moreover, a long-lasting severe

post-transplant thrombocytopenia is often observed even in pediatric patients [1-8].

Therefore, two important aspects of the biology of exvivo expanded cells relate to cultured cells: either maintaining their self-renewal capacity and multilineage differentiation

Correspondence: Wanda Piacibello, M.D., University of Torino Medical School, Department of Oncological Sciences, Institute for Cancer Research and Treatment, Laboratory of Clinical Oncology, Prov. 142, 10060 Candiolo, Torino, Italy. Telephone: 39-011-9933349; Fax: 39-011-9933522; e-mail: wanda.piacibello@ircc.it Received July 1, 2003; accepted for publication October 7, 2003. (C)AlphaMed Press 1066-5099/2004/\$12.00/0
\end{abstract}

Stem Cells 2004;22:135-143 www.StemCells.com 
potential, or improving their short-term engraftment ability when transplanted into myeloablated recipients. Several growth factor combinations have been tested to identify suitable culture conditions to induce expansion of primitive stem cells (SCs). So far, only a few studies have shown that primitive non-obese diabetic severe combined immunodeficient (NOD/SCID) mouse repopulating stem cells from $\mathrm{CB}$ can be expanded (a few or several-fold) after in vitro culture [9-13].

In $\mathrm{CB}$ transplants, the megakaryocyte (Mk) lineage takes the longest time to engraft. However, to date, if only a few experimental studies have addressed the issue of the short-term engraftment ability of fresh CB SCs, even fewer have addressed that of ex-vivo expanded SCs [14-16]. Using the NOD/SCID mouse model, the short-term as well as the long-term repopulating ability and the differentiation and maturation potential of human hematopoietic lineages in an in vivo experimental model can be analyzed [17, 18].

Thus, by means of this in vivo model we set up experiments to evaluate the $\mathrm{Mk}$ lineage reconstitution ability and functional platelet release by baseline $\mathrm{CB} \mathrm{CD} 34^{+}$cells $\left(b 34^{+}\right)$ and $\mathrm{CB} \mathrm{CD} 34^{+}$cells reisolated after a 4-week expansion $\left(4 w 34^{+}\right)$in the presence of Flt-3 ligand (FL), thrombopoietin (TPO), and stem cell factor (SCF).

\section{Materials ANd Methods}

\section{Recombinant Human Cytokines}

The following recombinant purified human cytokines were used in these studies: recombinant human (rh) TPO, a generous gift from Kirin Brewery (Tokyo, Japan; http://www.kirin.co.jp/english/), rh interleukin-6 (IL-6) (PeproTech Inc.; Rocky Hill, NJ; http://www.peprotech. com), rhIL-3 (Sandoz; Basel, Switzerland; http://www.sandoz.com), rhFL kindly provided by S.D. Lyman (Immunex Corp; Seattle, WA; http://www.immunex.com), and rhSCF (a gift from Amgen; Thousand Oaks, CA; http://www.amgen. com).

\section{Human Cells}

Umbilical CB was obtained following informed written consent at the end of full-term deliveries, by clamping and cutting the cord and draining blood into sterile collection tubes containing the anticoagulant citrate-phosphate dextrose.

\section{CD34 ${ }^{+}$Cell Purification and Culture}

Mononuclear cells were isolated from CB using Ficoll Hypaque (density $1.077 \mathrm{~g} / \mathrm{cm}^{3}$; [Nyegaard; Oslo, Norway; http://www.amershamhealth.com]) density centrifugation. The $\mathrm{CD}_{3} 4^{+}$fraction was isolated with superparamagnetic microbead selection using high-gradient magnetic field and MiniMACS column (Miltenyi Biotech; Gladbach, Germany; http://www.miltenyibiotech.com). The efficiency of the purification was verified by flow cytometry counter staining with a CD34-phycoerythrin (PE) HPCA-2 antibody (Becton Dickinson; San Jose, CA; http://www.bd.com). In the cell fraction containing purified cells, the percentage of $\mathrm{CD} 34^{+}$cells ranged from $90 \%-98 \%$. These cells were denominated $b 34^{+}$.

\section{Long-Term Expansion Cultures for Primitive Repopulating Cells}

Stroma-free expansion cultures were performed as previously described $[11,19,20]$. Briefly, CB CD $34^{+}$cells at $5 \times$ $10^{4} / \mathrm{ml}$ in Iscove's modified Dulbecco's medium (GIBCO) with $10 \%$ fetal calf serum (HyClone; Logan, UT; http://www.hyclone.com) were inoculated into tissue culture $\mathrm{T}_{75}$ flasks with FL (50 ng/ml), SCF (50 ng/ml), and TPO (10 $\mathrm{ng} / \mathrm{ml}$ ). Growth factors were added at the start of cultures and then twice a week. Each week the cells were counted and the same volume of fresh medium plus growth factors was added. After 4 weeks all cells were harvested, washed, counted, and then subjected to immunoselection with MiniMACS columns as described above, to obtain $\mathrm{CD} 34^{+}$populations (denominated $4 w 34^{+}$) to be injected into sublethally irradiated NOD/SCID mice. $4 w 34^{+}$cells were $96 \%-98.7 \%$ pure; only $1.5 \%-2.8 \%$ of these cells were $\mathrm{CD} 34^{+} / \mathrm{CD} 41^{+}$.

\section{Injection of Cells in NOD/SCID Mice}

NOD/LtSz scid/scid NOD/SCID mice were purchased from The Jackson Laboratory (Bar Harbor, ME; http://www. jax.org) and maintained in the Centro di Immunologia ed Oncologia Sperimentale animal facilities (Torino, Italy). All animals were handled under sterile conditions and maintained in cage microisolators. Sublethally irradiated (350 cGy of total body irradiation from a ${ }^{137} \mathrm{Cs}$ source) 6 - to 8 -week-old mice were injected in the tail vein with $2.5 \times 10^{5} \mathrm{~b} 34^{+}$or 2.5 $\times 10^{5} 4 w 34^{+}$cells. The mice were sacrificed $1,2,3$, and 4 weeks (short-term reconstitution) post-transplant or after a longer period of time ( 6 to 8 weeks post injection), and bone marrow (BM) cells were flushed from femurs and tibias using a syringe and 26-gauge needle to assess the number and types of human cells.

The appearance of human platelets (HuPlts) in murine peripheral blood $(\mathrm{PB}) 7,14,21$, and 28 days after injection was also assessed as described [21]. No growth factors were administered to the animals.

Serial transplant experiments were performed as previously described [22]. Briefly, 20 to $40 \times 10^{6}$ unseparated BM cells from a primary or a secondary mouse were injected i.v. into a single sublethally irradiated secondary or tertiary NOD/SCID mouse. Secondary and tertiary mice were sacrificed 6 weeks post injection, and BM cells were harvested and processed as described. 


\section{Analysis of Murine BM}

Flow cytometry was used to analyze the levels of human cells in the BM of the mice; the cells were resuspended at 1 to $2 \times 10^{6}$ cells $/ \mathrm{ml}$ and incubated with mouse immunoglobulin G (Fluka Chemika Biochemika; Buchs, Switzerland; http://www.wiz.uni-kassel.de) to block nonspecific binding to the Fc receptor. Cells were then incubated with fluorescein isothiocyanate (FITC) or PE-labeled monoclonal antibody (mAb) specific for human $\mathrm{CD}$ for 30 minutes at $4^{\circ} \mathrm{C}$ to quantify human hematopoietic cells. Some cells from each suspension were similarly incubated with isotype control mAbs labeled with FITC and PE (CALTAG Laboratory; Burlingame, CA; http://www.cal tag.com). After staining the cells were washed once in phosphate-buffered saline with $0.1 \%$ bovine serum albumin and $0.01 \%$ sodium azide. Contaminating RBCs were lysed with EDTA $10^{-4} \mathrm{~mol} / \mathrm{l}, \mathrm{KHCO}_{3} 10^{-3} \mathrm{~mol} / \mathrm{l}$, and $\mathrm{NH}_{4} \mathrm{CL} 0.17$ mol/l. Flow cytometric analysis was performed using a FACSVantage cytometer (Becton Dickinson). At least 20,000 events were acquired for each analysis. Analysis was performed with CellQuest software (Becton Dickinson).

The antibodies used were FITC-labeled antihuman CD41, CD42 (DAKO; Glostrup, Denmark; http://www.dakocy tomation.com), and PE-labeled antihuman CD14 (DAKO), CD19 (CALTAG Laboratory), CD34 (Becton Dickinson), CD71 (DAKO), and anti-GpA (DAKO). CD45 TRI-COLOR conjugated (CALTAG Laboratory) was also used.

For human colony assays, 1 to $5 \times 10^{5} \mathrm{BM}$ cells, according to the levels of human engraftment, were plated in plasma clot assays as previously reported [11] by substituting bovine plasma with pooled human AB plasma. Human GM and erythroid colonies were enumerated after 14 days of incubation at $37^{\circ} \mathrm{C}$ in a fully humidified atmosphere at $5 \% \mathrm{CO}_{2}$ from triplicate dishes containing erythropoietin (3 U/ml), SCF (50 ng/ml), GM-CSF (20 ng/ml), and IL-3 $(5 \mathrm{ng} / \mathrm{ml})$. Colony-forming units (CFU-Mk) were enumerated after 12 days of cultures from triplicate dishes at the immunofluorescence microscope after staining with an FITC-conjugated $\mathrm{mAb}$ recognizing human GP IIb/IIIa (CD41) [23, 24]. In the described culture conditions only human colonies could be detected. At the various time points $\mathrm{BM}$ cells from irradiated and not transplanted NOD/SCID mice were cultured, but in no case could human colonies be detected.

\section{Human Platelet Detection in NOD/SCID Mouse Peripheral Blood}

Platelet appearance in murine PB 7, 14, 21, and 28 days after injection was also assessed as described [21]. Briefly, murine PB $(10 \mu \mathrm{l})$ was incubated at room temperature with
FITC-conjugated anti-mouse CD41 (Becton Dickinson) and PE-conjugated anti-human CD41 (DAKO) or isotype control for 5 minutes and analyzed immediately by flow cytometry. Fifty-thousand events were acquired with a primary gate set on a dual parameter histogram of log forward light scatter and log side light scatter. Background fluorescence was assessed with platelets labeled with the FITCand PE-conjugated isotype control antibody. PB from untransplanted mice and from a human donor was analyzed as additional controls. A FACSVantage flow cytometry (Becton Dickinson) was used for acquisition of platelet data, and analysis was performed using CellQuest software (Becton Dickinson).

\section{Activation of Human Platelets by Thrombin}

Aliquots of mouse PB $(10 \mu \mathrm{l})$ were incubated with thrombin (at a final concentration of $50 \mathrm{U} / \mathrm{ml}$ ) for $10 \mathrm{~min}$ utes. After this incubation the platelet CD62P (CALTAG Laboratory) expression was assessed by flow cytometry. Live acquisition of 1,000 to 2,000 HuPlts events was performed by gating human $\mathrm{CD}_{4} 1 \mathrm{PE}^{+}$events in the platelet size range.

\section{Statistical Analysis}

Results of experimental points obtained from multiple experiments are reported as the mean \pm standard deviation (SD). The significance of differences in mean value was determined by using the Student's $t$-test.

\section{RESUlts}

\section{Megakaryocyte Reconstitution in NOD/SCID Mice by Baseline and Expanded CD34+ Cells ( $b 34^{+}$and $\left.4 w 34^{+}\right)$}

To evaluate short-term Mk-engraftment, $2.5 \times 10^{5} \mathrm{b34}^{+}$ cells were injected into cohorts of sublethally irradiated NOD/SCID mice that were sacrificed 1, 2, and 3 weeks after inoculation. BM cells of the sacrificed animals were obtained from both femurs and tibias and assessed for the presence of human hematopoietic cells. Human cells in the murine BM were quantified for myeloid, lymphoid, erythroid, and Mk lineage antigen expression. Fluorescenceactivated cell sorter (FACS) analysis of the BM of the sacrificed animals showed that at week 1 post-transplant levels of human $\mathrm{CD} 45^{+}$cells were low but clearly detectable $(3.7 \pm 2.8)$. Within the human cells, the most represented were the $\mathrm{CD}_{3} 4^{+}$and the $\mathrm{CD} 19^{+}$subpopulations (Table 1). Erythroid cells, identified by CD71 and GpA expression were also present. Surprisingly, no cells belonging to the Mk lineage could be found. At week 2 post injection, the levels of human $\mathrm{CD} 45^{+}$cells were quite similar. At week 3 , human cell engraftment further increased. Only at 
Table 1. Short-term engraftment of NOD/SCID mice transplanted with fresh $\left(b 34^{+}\right)$or ex vivo expanded $\left(4 w 34^{+}\right)$cells

\begin{tabular}{|c|c|c|c|c|c|c|}
\hline \multirow[b]{2}{*}{ Engraftment (\%) } & \multicolumn{3}{|c|}{$b 34^{+}$cells } & \multicolumn{3}{|c|}{$4 w 34^{+}$cells } \\
\hline & 7 days & 14 days & 21 days & 7 days & 14 days & 21 days \\
\hline $\mathrm{CD} 45^{+}$ & $3.7 \pm 2.8$ & $4 \pm 2.1$ & $7.3 \pm 1.5$ & $2.7 \pm 1.9$ & $5.6 \pm 3.3$ & $6.9 \pm 2.5$ \\
\hline $\mathrm{CD} 34^{+}$ & $1.1 \pm 0.5$ & $1.2 \pm 0.5$ & $0.9 \pm 0.4$ & $1.2 \pm 0.7$ & $1.1 \pm 0.5$ & $0.9 \pm 0.2$ \\
\hline $\mathrm{CD} 19^{+}$ & $1.2 \pm 0.7$ & $1.6 \pm 0.8$ & $3.5 \pm 1.4$ & $0.9 \pm 0.4$ & $2.4 \pm 1.1$ & $3 \pm 1.2$ \\
\hline $\mathrm{CD}^{+} 3^{+}$ & $0.8 \pm 0.4$ & $0.9 \pm 0.5$ & $1.2 \pm 0.3$ & $0.4 \pm 0.1$ & $0.9 \pm 0.3$ & $1.2 \pm 0.8$ \\
\hline $\mathrm{CD} 41^{+}$ & $0^{*}$ & $0^{*}$ & $0.4 \pm 0.2$ & $0^{*}$ & $0.3 \pm 0.1$ & $0.8 \pm 0.3$ \\
\hline $\mathrm{CD} 71^{+} \mathrm{GpA}^{+}$ & $0.3 \pm 0.1$ & $0.3 \pm 0.1$ & $0.8 \pm 0.4$ & $0.2 \pm 0.1$ & $0.4 \pm 0.2$ & $1.3 \pm 0.3$ \\
\hline Total colonies/mouse ${ }^{\S}$ & $1,945 \pm 32$ & $2,102 \pm 32$ & $2,307 \pm 65$ & $2,456 \pm 43$ & $4,986 \pm 56^{* *}$ & $5,011 \pm 43^{* *}$ \\
\hline Mk-colonies/mouse ${ }^{\dagger}$ & 0 & $42 \pm 23$ & $73 \pm 28$ & $72 \pm 15^{* *}$ & $210 \pm 32^{* *}$ & $259 \pm 34^{* *}$ \\
\hline
\end{tabular}

Mice were injected with $2.5 \times 10^{5}\left(b 34^{+}\right)$cells and with the same number of CD34+ cells immunoselected from week 4 expansion cultures $\left(4 w 34^{+}\right)$. Results show the mean \pm SD of human cell subpopulations detected by FACS analysis performed in the murine BM 1,2, and 3 weeks after transplant (4 mice per experimental point, 3 separate experiments).

"Below FACS detection limit $(<0.1 \%$ of human cells).

${ }^{\S}$ Mean \pm SD of the number of human CFU-GM + BFU-E + CFU-GEMM + CFU-Mk calculated/mouse. The number was obtained by plating 1 to 5 $\times 10^{5}$ total BM cells of the engrafted mice (three dishes per point), taking into account that BM cells of femurs and tibias represent $25 \%$ of the entire BM [31]. Colony number was calculated by multiplying the mean number of colonies generated by $5 \times 10^{5}$ unseparated mouse BM cells $\times$ the number of cells harvested from the femurs and the tibias of each mouse $\times 4$ and by dividing the total number by $5 \times 10^{5}$.

${ }^{\dagger}$ CFU-Mk were separately scored on day 12 at the immunofluorescence microscope, after staining of three additional dishes with FITC-conjugated anti-human GP IIb/IIIa monoclonal antibody.

${ }^{* *} p<0.05$ as compared to the values obtained injecting $b 34^{+}$.

this time point the Mk subpopulation, although at very low percentages, became detectable (Table 1).

To evaluate the short-term Mk-engraftment capacity of more expanded primitive cells, in five different experiments, $2.5 \times 10^{5} \mathrm{CD} 34^{+}$cells were cultured in triplicate stroma-free liquid cultures in the presence of FL, SCF, and TPO as described [11]. After 4 weeks of expansion they yielded a mean of $48.5 \pm 2.4 \times 10^{6}$ total cells that included $1.9 \pm 0.43 \times 10^{6} \mathrm{CD} 34^{+}$cells. Following immunoselection, only $2.5 \times 10^{5} \mathrm{CD} 34^{+}\left(4 w 34^{+}\right)$cells were injected in each mouse. In these mice the levels of human engraftment at week 1 were similar to those found in $b 34^{+}$-transplanted mice and increased with time. Here the growth of some CFU-Mk colonies could be achieved. CFU-Mk number increased at weeks 2 and 3 (Table 1). By contrast, in mice injected with b34 $4^{+}$cells, no CFU-Mk colonies could be found at week 1 . Only at week 3 were there as many Mk colonies as those found much earlier (week 1) in 4 w34+ transplanted mice.

Long-term Mk-engraftment was evaluated in NOD/SCID mice sacrificed 6-8 weeks after inoculation. Table 2 shows the mean engraftment level of ten mice injected with $2.5 \times 10^{5}$ $b 34^{+}$cells. Flow cytometry analysis showed that the human cells belonged to all hematopoietic lineages; cells of the Mk lineage were found in all mice. CFU-Mk colonies were detected in plasma clot cultures seeded with the BM cells of the transplanted animals (Table 2).
The results of injection of $2.5 \times 10^{5} 4 w 34^{+}$cells are reported in Table 2. All the mice, after 6-8 weeks from the injection, were successfully engrafted (10/10). The mean engraftment level of the ten mice injected with this cell dose was $15 \pm 5 \%$. FACS analysis showed that human cells belonged to all hematopoietic lineages (not shown).

Moreover, five mice were transplanted with all of the $\mathrm{CD}_{4} 4^{+}$cells generated by initial $2.5 \times 10^{5} \mathrm{CD} 34^{+}$cells during a 4-week expansion. At 6-8 weeks post-transplant the BM engraftment levels were very high $(79 \pm 11.4)$ and the Mk population was well-represented $(3.6 \pm 0.4 \%$ of the total $\mathrm{BM})$.

The presence of human CFU-Mk in the BM of mice was evaluated. Overall, $1,900 \pm 302,2,200 \pm 159$ and 8,259 $\pm 1,102$ human $\mathrm{Mk}$ colonies were detected in mice transplanted with $b 34^{+}$and the two concentrations of $4 w 34^{+}$cells, respectively.

To evaluate the effective long-term Mk-engraftment of expanded cells, the unseparated BM cells of three primary mice, harvested 6 weeks after injection of $2.5 \times 10^{5} 4 \mathrm{w} 34^{+}$ cells, were transplanted in three secondary and subsequently in three tertiary sublethally irradiated recipients. In these experiments of serial transplants, mice were successfully engrafted, and the Mk population was well-represented [22] (Fig. 1).

\section{Platelet Production in NOD/SCID Mice}

The appearance of HuPlts in the mouse PB after CB injection was monitored from week 1 by FACS analyses. After total 
Table 2. Six- to 8-week engraftment of NOD/SCID mice transplanted with b34+ and $4 \mathrm{w} 34^{+} \mathrm{CB}$ cells

\begin{tabular}{|c|c|c|c|}
\hline Engraftment $(\%)$ & b34+ cells $\left(2.5 \times 10^{5}\right)$ & $4 \mathrm{w} 34^{+}$cells $\left(2.5 \times 10^{5}\right)$ & tot 4 w34 $4^{+}$cells $\left(2.15 \pm 1.7 \times 10^{6}\right)$ \\
\hline $\mathrm{CD}^{4} 5^{+}$ & $11.9 \pm 3.5^{*}$ & $15 \pm 5$ & $79 \pm 11.4$ \\
\hline $\mathrm{CD}_{3} 4^{+}$ & $1.3 \pm 0.5$ & $1.5 \pm 0.9$ & $7.1 \pm 3.6$ \\
\hline $\mathrm{CD} 9^{+}$ & $6.1 \pm 3.1$ & $7.6 \pm 2.3$ & $50 \pm 9.8$ \\
\hline $\mathrm{CD} 3^{+}$ & $1.9 \pm 0.7$ & $2.3 \pm 1.3$ & $15 \pm 4.5$ \\
\hline $\mathrm{CD} 41^{+}$ & $1.3 \pm 0.5$ & $1.6 \pm 0.5$ & $3.6 \pm 0.4$ \\
\hline $\mathrm{CD} 71^{+} \mathrm{GpA}^{+}$ & $0.8 \pm 0.4$ & $1 \pm 0.5$ & $2.5 \pm 1.1$ \\
\hline Human colonies/mouse & $31,700 \pm 2,200$ & $52,200 \pm 1,600^{* *}$ & $125,600 \pm 13,600^{\dagger}$ \\
\hline Human CFU-Mk/mouse & $1,900 \pm 300$ & $2,200 \pm 150^{* *}$ & $8,250 \pm 1,100^{\dagger}$ \\
\hline
\end{tabular}

*Ten mice were injected with $2.5 \times 10^{5}$ b34 $4^{+}$cells, 10 mice with $4 \mathrm{w} 34^{+} 2.5 \times 10^{5}$ cells, and five mice with all of the CD34 $4^{+}$cells generated by initial $2.5 \times 10^{5} \mathrm{CD} 34^{+}$cells after 4 weeks of ex vivo expansion with FL, SCF, and TPO $\left(1.93\right.$ to $\left.2.35 \times 10^{6} 4 \mathrm{w} 34^{+}\right)$.

Results are expressed as the mean \pm SD of $\%$ of human cells observed with FACS analyses performed on murine BM 6 to 8 weeks after transplant. Colony counts were performed as described in Table 1, with the exception that for each dish, $1 \times 10^{5}$ unseparated mouse BM cells were plated.

Results are from five separate expansion experiments (two mice per experiment).

*** not significant

${ }^{\dagger} p<0.05$ compared to values obtained by inoculating $b 34^{+}$cells

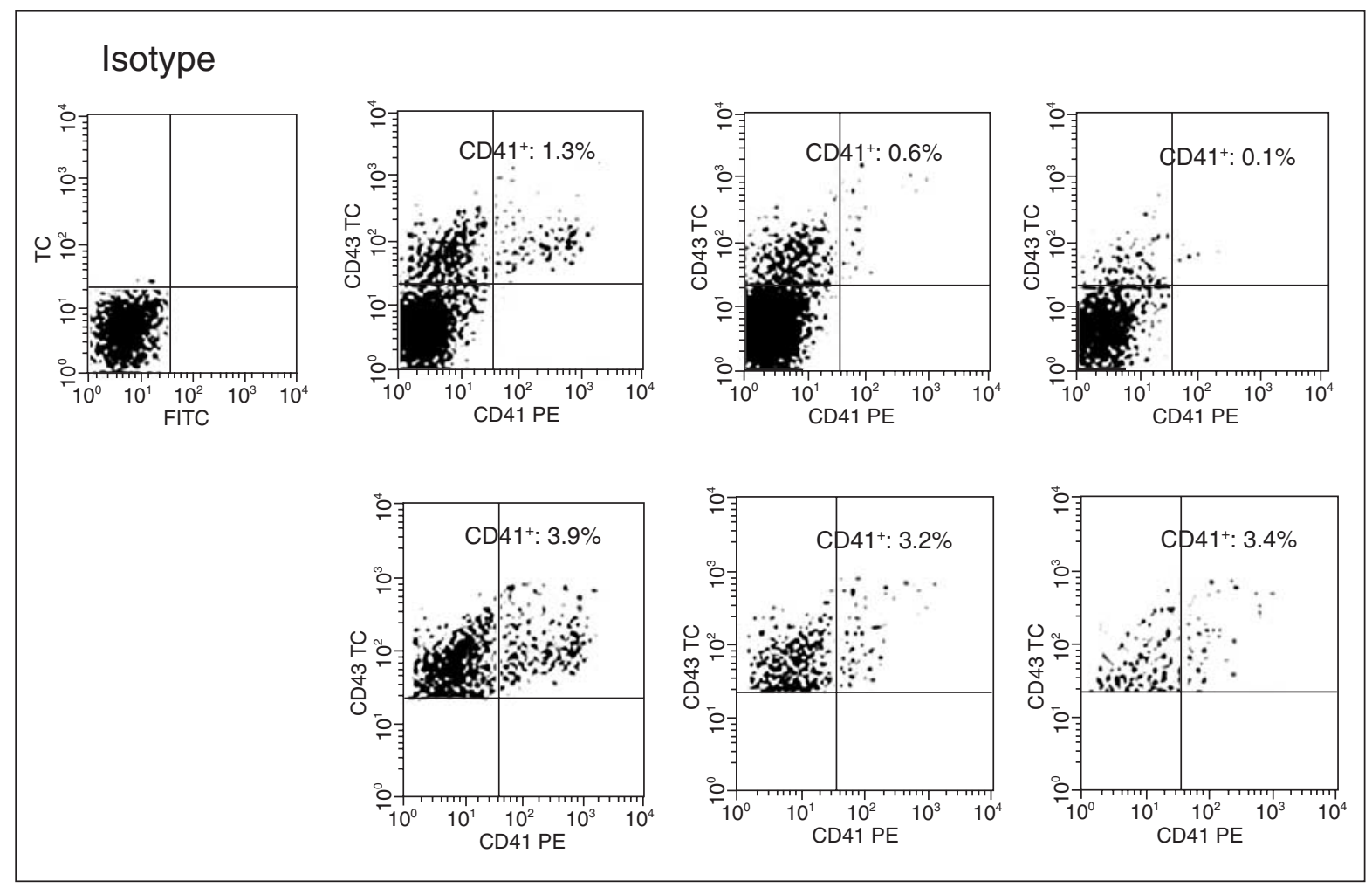

Figure 1. Human megakaryocyte engraftment in serial transplant NOD/SCID mice. FACS profile of marrow cells from a representative $N O D / S C I D$ mouse that 6 weeks earlier was transplanted with $2.5 \times 10^{5} 4 \mathrm{wCD} 34^{+}\left(C D 34^{+}\right.$cells immunoselected after 4 weeks of expansion in presence of FL, SCF, and TPO). The BM of this primary mouse was injected into a secondary sublethally irradiated NOD/SCID mouse sacrificed 6 weeks after transplantation; the BM of this mouse was injected in a tertiary mouse also sacrificed 6 weeks after transplantation. Human $C D 45^{+}$cells represented $22 \%$ of the BM cells of the primary mouse, $7 \%$ of the secondary recipient that had received $25 \times 10^{6}$ unseparated BM cells of the primary mouse, and $2.5 \%$ of the tertiary mouse that received $30 \times 10^{6}$ total BM cells of the secondary recipient. FACS analyses of human CD41 expression in the BM of primary, secondary, and tertiary mice were performed on total BM: the percentages of CD $41^{+}$cells were respectively: $1.3 \%, 0.6 \%$, and $0.1 \%$. The bottom panels represent the analysis of the $C D 41^{+}$population within the $C D 45^{+}$cell gate in each of the three recipients. 


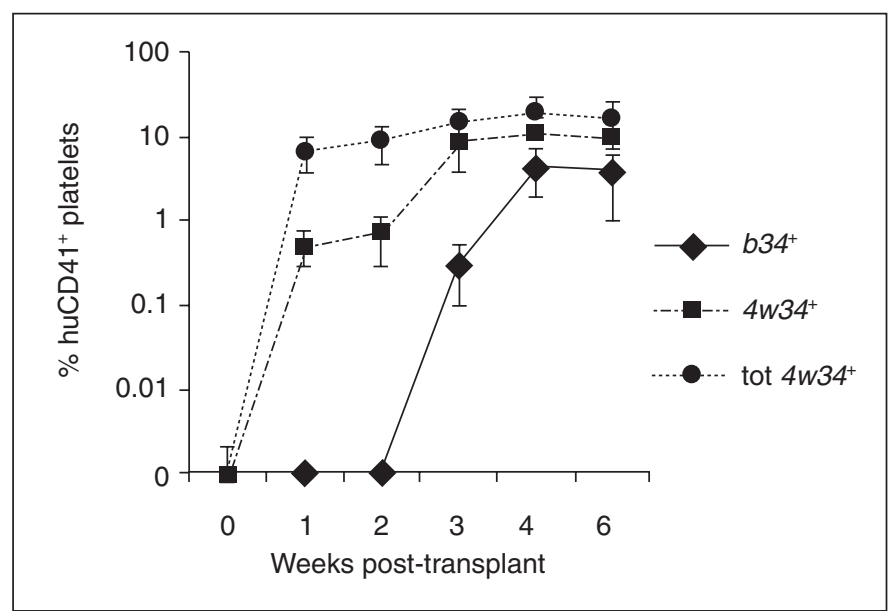

Figure 2. Human platelet appearance. Kinetics of HuPlt appearance in the PB of NOD/SCID mice injected with $2.5 \times 10^{5}$ baseline CD $34^{+}$cells, $2.5 \times 10^{5} \mathrm{CD} 34^{+}$ cells immunoselected from 4-week expanded cultures and with all the CD34+ progeny of $2.5 \times 10^{5}$ initial $C D 34^{+}$cells expanded for 4 weeks. Results show the mean $\pm S D$ of the percentage of HuPlts detected by FACS analysis in the murine $P B$ at the indicated time points after transplantation (4 mice per experimental point, 3 separate experiments).

body irradiation murine platelets decreased from a mean of $1.45 \pm 0.3 \times 10^{12} / \mathrm{l}$ to a mean of $0.45 \pm 0.1 \times 10^{12} / 1$ at week 1 and increased to a mean of $0.8 \pm 0.2 \times 10^{12} / 1$ at week 3 .

HuPlts were detected by staining PB cells with an antiCD41 mAb against HuPlts surface GP IIb/IIIa. After transplantation of $b 34^{+}$cells, a maximum of $0.3 \%$ HuPlts was detected only at week 3 (Fig. 2). At week 4 HuPlt count was a mean of $4.5 \%$; the percentage of the HuPlts was similar at 6-8 weeks after transplant in some transplanted mice. By contrast in the PB of mice injected with $2.5 \times 10^{5} 4 w 34^{+}$cells, $0.5 \%$ of HuPlts were seen as early as week 1 , even if the human $\mathrm{CD} 41^{+}$cells in the murine BM were below the FACS detection limit $(<0.1 \%)$. Plts were a mean of $0.7 \%$ at week 2 and $12 \%$ at week 3 (Fig. 2 and Fig. 3A). The HuPlts persisted in murine PB even 6-8 weeks after transplant. When the mice were transplanted with all of the $4 w 34^{+}$cells generated by initial $2.5 \times 10^{5} \mathrm{CD} 34^{+}$cells, platelet levels at week 1 were very high (6.8\%) (Fig. 2).

HuPlt activation in response to in vitro challenge with thrombin was tested. Thrombin induces granule secretion resulting in CD62P expression on the platelet membrane. After thrombin stimulation, the expression of CD62P on human $\mathrm{CD} 41^{+}$platelets was increased (Fig. 3B).

\section{Discussion}

The xenogenic NOD/SCID mouse model offers one of the best approaches for investigating the in vivo repopulating ability of human hematopoietic tissues [14-16, 25-28]. In such a model we previously demonstrated that $\mathrm{CB} C D 34^{+}$cells could be expanded for several weeks in stroma-free cultures containing FL, TPO, and SCF and that expanded cells maintained and increased their in vivo repopulating capacity [11, $12,22]$. Moreover, we have previously demonstrated that basal and expanded CD $34^{+}$cells, subsequently "committed" in vitro toward the Mk lineage, gave a rapid and transient Mk engraftment [29].

In this work $\mathrm{CB} \mathrm{CD} 34^{+}$cells, isolated after 4 weeks of expansion $\left(4 w 34^{+}\right.$cells), were injected in NOD/SCID mouse recipients. These experiments show that purified $4 w 34^{+}$cells retain their capacity to provide long-term support of the megakaryocytopoiesis in the $\mathrm{BM}$ of several generations of sublethally irradiated NOD/SCID mice. The levels of human hematopoietic reconstitution were similar in mice transplanted with same numbers of $b 34^{+}$and $4 w 34^{+} \mathrm{CB}$ cells (or slightly higher with the expanded cells). As already reported, all hematopoietic lineages including the $\mathrm{Mk}$, were found in the NOD/SCID mice BM at least 6 to 8 weeks post-transplant of expanded cells [11]. The Mk lineage was represented by $\mathrm{CD} 41^{+}$cells and by more immature $\mathrm{CFU}-\mathrm{Mk}$.

Although previous studies reported that human $\mathrm{CB}, \mathrm{BM}$, and PB could generate human CD41 ${ }^{+}$cells in NOD/SCID mice [16, 29], only a few papers have provided evidence for human $\mathrm{Mk}$ development and terminal differentiation into functional HuPlts with human CD34+ $\mathrm{PB}$ and $\mathrm{CB}$ cells [14, 15]. To our knowledge this research is the first that shows expanded CB cells are better than unmanipulated cells in terms of Mk short-term engraftment and terminal Mk maturation (platelets production was already found 1 week after the injection of ex vivo expanded CD34+ cells).

In fact, these studies indicate that short-term engraftment is achieved with both baseline and expanded CD $34^{+}$cells. Furthermore, while Mk reconstitution is slower with $b 34^{+}$ cells (a few Mk cells and CFU-Mk appear in the BM, and platelets are found in the PB only at week 3 and 2 post-transplant, respectively), Mk-engraftment by purified $4 w 34^{+}$cells is detectable earlier. The speed and degree of Mk-engraftment by expanded cells are higher in the latter case. Terminal differentiation of $\mathrm{Mk}$ progenitors and precursors is also achieved in this case, as HuPlts are well detected in the PB from week 1 on. Probably at 1 week post-injection in the BM of $4 w 34^{+}$transplanted mice and at week 2 post-injection in the $\mathrm{BM}$ of $b 34^{+}$transplanted mice, there were a few human $\mathrm{CD} 41^{+}$cells that were able to produce platelets, but the level in total BM (murine and human cells) is below the FACS detection limits.

Our findings on $b 34^{+}$cells are consistent with those reported by Verstegen et al. who found peak, but low levels, of HuPlts at week $2(0.1 \%$ to $0.2 \%)$ in macrophagedepleted SCID mice injected with CB CD34+ cells [15]. A previous study by Güenechea et al. reported that day 


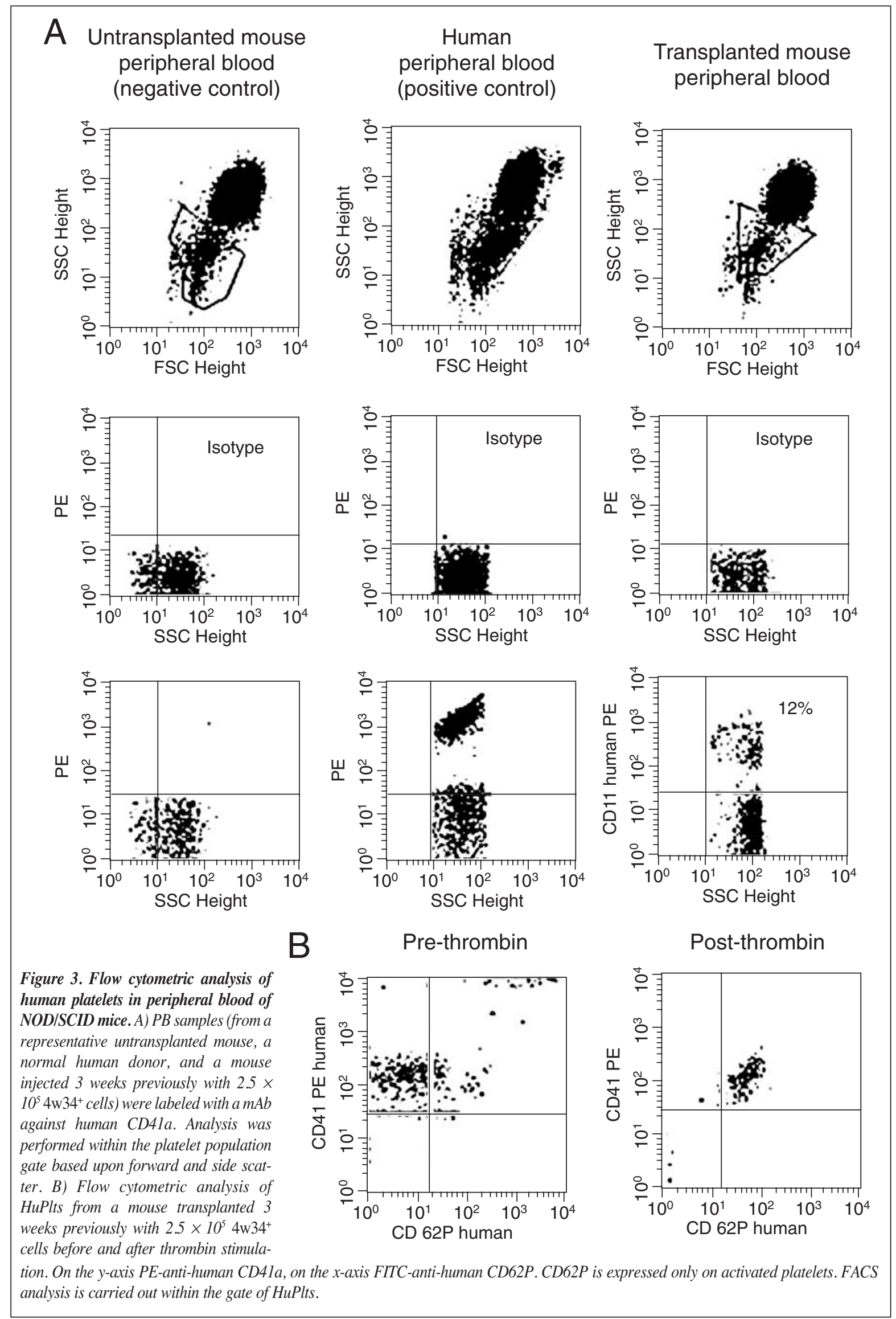


7-expanded CB cells engraft in the NOD/SCID mouse more slowly than the unmanipulated counterpart [30]. Our data indicate that even equal numbers of expanded and reisolated $\mathrm{CD} 34^{+}$cells, compared to baseline $\mathrm{CB}$ cells, provide similar engraftment at 1,2, and 3 weeks post-transplant in terms of total $\mathrm{CD} 45^{+}$cells and a faster Mk reconstitution. If baseline cells and the entire expansion equivalents obtained in the present setting are compared, then marrow engraftment at both early time points ( $25 \% \mathrm{CD}^{2} 5^{+}$at week 1$)$ and at the standard 6-8 weeks is much higher with $4 \mathrm{w} 34^{+}-$ expanded cells. Culture conditions, in particular growth factor combinations employed in the two studies, are quite different, and this explains the opposite findings. This suggests that several aspects of cell expansion and manipulation must be carefully studied, especially the growth factor combinations to be adopted, before a clinical protocol is implemented.

In conclusion, by means of serial transplants we show that ex-vivo expanded cells are capable of sustained long-term Mkengraftment. Short-term engraftment by ex vivo expanded cells seems even more efficient than with unmanipulated cells.

\section{ACKNOWLEDGMENTS}

Support for this work was provided by grants from the Associazione Italiana per la Ricerca sul Cancro (AIRC), Milan, Italy and from the Ministero dell'Università e della Ricerca Scientifica e Tecnologica (MURST), Rome to W.P. and to M.A., and from CNR (Progetto Finalizzato Oncologia). The authors wish to thank Mrs. L. Ramini for invaluable secretarial assistance.

\section{REFERENCES}

1 Gluckman E. Hematopoietic stem-cell transplant using umbilical-cord blood. N Engl J Med 2001;344:1860-1861.

2 Laughlin MJ, Barker J, Bambach B et al. Hematopoietic engraftment and survival in adult recipients of umbilical-cord blood from unrelated donors. N Engl J Med 2001;344:1815-1822.

3 Gluckman E, Rocha V, Boyer-Chammard A et al. Outcome of cord-blood transplantation from related and unrelated donors. Eurocord Transplant Group and the European Blood and Marrow Transplantation Group. N Engl J Med 1997;337:373-381.

4 Wagner JE, Kernan NA, Steinbuch M et al. Allogeneic sibling umbilical-cord-blood transplantation in children with malignant and non-malignant disease. Lancet 1995;346:214-219.

5 Kurtzberg J, Laughlin M, Graham ML et al. Placental blood as a source of hematopoietic stem cells for transplantation into unrelated recipients. N Engl J Med 1996;335:157-166.

6 Wagner JE, Rosenthal J, Sweetman R et al. Successful transplantation of HLA-matched and HLA-mismatched umbilical cord blood from unrelated donors: analysis of engraftment and acute graft-versus-host disease. Blood 1996;88:795-802.

7 Rubinstein P, Carrier C, Scaradavou A et al. Outcomes among 562 recipients of placental-blood transplants from unrelated donors. N Engl J Med 1998;339:1565-1577.

8 Gluckman E, Locatelli F. Umbilical cord blood transplants. Curr Opin Hematol 2000; 7:353-357.

9 Conneally E, Cashman J, Petzer A et al. Expansion in vitro of transplantable human cord blood stem cells demonstrated using a quantitative assay of their lympho-myeloid repopulating activity in nonobese diabetic-scid/scid mice. Proc Natl Acad Sci USA 1997;94:9836-9841.

10 Bhatia M., Bonnet D, Kapp U et al. Quantitative analysis reveals expansion of human hematopoietic repopulating cells after short-term ex vivo culture. J Exp Med 1997;186:619-624.

11 Piacibello W, Sanavio F, Severino A et al. Engraftment in nonobese diabetic severe combined immunodeficient mice of human $\mathrm{CD} 4^{+}$cord blood cells after ex vivo expansion: evidence for the amplification and self-renewal of repopulating stem cells. Blood 1999;93:3736-3749.

12 Ueda T, Tsuji K, Yoshino $\mathrm{H}$ et al. Expansion of human NOD/SCID-repopulating cells by stem cell factor, Flk2/Flt3 ligand, thrombopoietin, IL-6, and soluble IL-6 receptor. J Clin Invest 2000;105:1013-1021.

13 Kollet O, Aviram R, Chebath J et al. The soluble interleukin6 (IL-6) Receptor/IL-6 fusion protein enhances in vitro maintenance and proliferation of human $\mathrm{CD} 34^{+} \mathrm{CD} 38^{- \text {-low }}$ cells capable of repopulating severe combined immunodeficiency mice. Blood 1999;94:923-931.

14 Perez LE, Rinder HM, Wang C et al. Xenotransplantation of immunodeficient mice with mobilized human blood CD34 ${ }^{+}$ cells provides an in vivo model for human megakaryocytopoiesis and platelet production. Blood 2001;97:1635-1643.

15 Verstegen MM, van Hennik PB, Terpstra W et al. Transplantation of human umbilical cord blood cells in macrophage-depleted SCID mice: evidence for accessory cell involvement in expansion of immature $\mathrm{CD} 34^{+} \mathrm{CD} 38^{-}$cells. Blood 1998;91:1966-1976.

16 Cashman JD, Lapidot T, Wang JC et al. Kinetic evidence of the regeneration of multi-lineage hematopoiesis from primitive cells in normal human bone marrow transplanted into immunodeficient mice. Blood 1997;89:4307-4316.

17 Lowry PA, Shultz LD, Greiner DL et al. Improved engraftment of human cord blood stem cells in NOD/ltSz-scid/scid mice after irradiation or multiple-day injections into unirradiated recipients. Biol Blood Marrow Transplant 1996;2:15-23.

18 Wang JC, Lapidot T, Cashman JD et al. High level engraftment of NOD/SCID mice by primitive normal and leukemic hematopoietic cells from patients with chronic myeloid leukemia in chronic phase. Blood 1998;91:2406-2414.

19 Piacibello W, Sanavio F, Garetto L et al. Extensive amplification and self-renewal of human primitive hematopoietic stem cells from cord blood. Blood 1997;89:2644-2653. 
20 Piacibello W, Sanavio F, Garetto L et al. Differential growth factor requirement of primitive cord blood hematopoietic stem cell for self-renewal and amplification vs proliferation and differentiation. Leukemia 1998;12:718-727.

21 Macey MG, Carty E, Webb L et al. Use of mean platelet component to measure platelet activation on the ADVIA 120 haematology system. Cytometry 1999;38:250-255.

22 Piacibello W, Bruno S, Sanavio F et al. Lentiviral gene transfer and ex-vivo expansion of human primitive stem cells capable of primary, secondary and tertiary multilineage repopulation in NOD/SCID mice. Blood 2002;100:43914400 .

23 Aglietta M, Monzeglio C, Sanavio F et al. In vivo effect of human granulocyte-macrophage colony-stimulating factor on megakaryocytopoiesis. Blood 1991;77:1191-1194.

24 Piacibello W, Garetto L, Sanavio F et al. The effects of human FLT3 ligand on in vitro human megakaryocytopoiesis. Exp Hematol 1996;24:340-346.

25 Hogan CJ, Shpall EJ, McNulty O et al. Engraftment and development of human $\mathrm{CD} 34^{+}$-enriched cells from umbilical cord blood in NOD/ltSz-scid/scid mice. Blood 1997;90:85-96.
26 Larochelle A, Vormoor J, Hanenberg H et al. Identification of primitive human hematopoietic cells capable of repopulating NOD/SCID mouse bone marrow: implications for gene therapy. Nat Med 1996;2:1329-1337.

27 Bhatia M, Wang JC, Kapp U et al. Purification of primitive human hematopoietic cells capable of repopulating immunedeficient mice. Proc Natl Acad Sci USA 1997;94:5320-5325.

28 Lapidot T, Fajerman Y, Kollet O. Immune-deficient SCID and NOD/SCID mouse models as functional assays for studying normal and malignant human hematopoiesis. J Mol Med 1997;75:664-673.

29 Bruno S, Gunetti M, Gammaitoni L et al. In vitro and in vivo megakaryocyte differentiation of fresh and ex vivo expanded cord blood cells: rapid and transient megakaryocyte reconstitution. Haematologica 2003;88:379-387.

30 Güenechea G, Segovia JC, Albella B et al. Delayed engraftment of nonobese diabetic/severe combined immunodeficient mice transplanted with ex vivo-expanded human $\mathrm{CD} 34^{+}$cord blood cells. Blood 1999;93:1097-1105.

31 Cashman J, Bockhold K, Hogge DE et al. Sustained proliferation, multi-lineage differentiation and maintenance of primitive human haemopoietic cells in NOD/SCID mice transplanted with human cord blood. Br J Haematol 1997;98:1026-1036. 